\title{
Genetics of Tinnitus: Still in its Infancy
}

\author{
Barbara Vona ${ }^{1 *}$, Indrajit Nanda ${ }^{1}$, Wafaa Shehata-Dieler ${ }^{2}$ and Thomas Haaf ${ }^{1}$ \\ ${ }^{1}$ Institute of Human Genetics, Julius Maximilians University Würzburg, Würzburg, Germany, ${ }^{2}$ Plastic, Aesthetic and \\ Reconstructive Surgery, Department of Otorhinolaryngology, Comprehensive Hearing Center, University Hospital Würzburg, \\ Würzburg, Germany
}

OPEN ACCESS

Edited by:

Christopher R. Cederroth

Karolinska Institutet, Sweden

Reviewed by:

Alexandre Fort,

University Medical School of Geneva,

Switzerland

Guy Van Camp,

University of Antwerp, Belgium

*Correspondence:

Barbara Vona

barbara.vona@uni-wuerzburg.de

Specialty section:

This article was submitted to

Perception Science,

a section of the journal

Frontiers in Neuroscience

Received: 02 December 2016 Accepted: 10 April 2017

Published: 08 May 2017

Citation:

Vona B, Nanda I, Shehata-Dieler W and Haaf T (2017) Genetics of

Tinnitus: Still in its Infancy.

Front. Neurosci. 11:236.

doi: 10.3389/fnins.2017.00236
Tinnitus is the perception of a phantom sound that affects between 10 and $15 \%$ of the general population. Despite this considerable prevalence, treatments for tinnitus are presently lacking. Tinnitus exhibits a diverse array of recognized risk factors and extreme clinical heterogeneity. Furthermore, it can involve an unknown number of auditory and non-auditory networks and molecular pathways. This complex combination has hampered advancements in the field. The identification of specific genetic factors has been at the forefront of several research investigations in the past decade. Nine studies have examined genes in a case-control association approach. Recently, a genome-wide association study has highlighted several potentially significant pathways that are implicated in tinnitus. Two twin studies have calculated a moderate heritability for tinnitus and disclosed a greater concordance rate in monozygotic twins compared to dizygotic twins. Despite the more recent data alluding to genetic factors in tinnitus, a strong association with any specific genetic locus is lacking and a genetic study with sufficient statistical power has yet to be designed. Future research endeavors must overcome the many inherent limitations in previous study designs. This review summarizes the previously embarked upon tinnitus genetic investigations and summarizes the hurdles that have been encountered. The identification of candidate genes responsible for tinnitus may afford gene based diagnostic approaches, effective therapy development, and personalized therapeutic intervention.

Keywords: complex disorders, genetics, genetic heterogeneity, genome-wide association study (GWAS), hearing loss, tinnitus, twin study

\section{INTRODUCTION}

Tinnitus is described as a scientific and clinical enigma that affects $10-15 \%$ of the general population. Furthermore, $\sim 1-3 \%$ of the population can be diagnosed with debilitating tinnitus connected to sleep disturbances, psychiatric distress, and quality of life consequences (Deniz et al., 2010; Shargorodsky et al., 2010; Baguley et al., 2013). Without question, the personal and societal strain from debilitating tinnitus can be enormous. The American Tinnitus Society describes the annual personal financial burden of tinnitus to be as high as $\$ 30,000$ from compounded healthcare costs, lost income, and reduced productivity (https://www.ata.org/understanding-facts/impacttinnitus).

Tinnitus is perceived as ringing, buzzing, beeping, or hissing and is characterized according to various clinical criteria. It can be subjective (perceived by the affected individual) or objective (heard by an observer), continuous or episodic, unilateral or bilateral, or pulsatile (synchronous or 
asynchronous). It can range from low- to high-intensity sound and can manifest any frequency. Tinnitus can be acute $(<3$ months), sub-acute (3-6 months), or chronic (>12 months) with a gradual or sudden onset or be associated with other triggers or comorbidities (Baguley et al., 2013). In combination, these features complicate precise tinnitus phenotyping and have hampered research aiming to uncover a genetic basis for tinnitus.

Risk factors of tinnitus include hearing loss, sound exposure, stress, anxiety, depression, ototoxic drugs, hypertension, and aging. While the association between individual risk factors and tinnitus is not straightforward, tinnitus seems to be correlated with advancing age and hearing loss (Baguley et al., 2013). Interestingly, only about half of patients with tinnitus have recognized risk factors, which is a reason it has been hypothesized that predisposition to tinnitus is linked with genetic background (Shargorodsky et al., 2010).

Secondary tinnitus has been conventionally recognized as a symptom of a variety of monogenic disorders for which many genes or loci have already been identified (Table 1). In contrast, recognition of chronic primary tinnitus may be obscured by nonMendelian inheritance patterns, which contribute to a lack of awareness and underreporting of tinnitus within families and among relatives (Sand et al., 2007). The association between genetic factors and primary tinnitus has historically lacked consensus and replication. Tinnitus could result from a number of pathological processes involving peripheral (cochlear) and/or central auditory abnormalities. The lack of consensus concerning these mechanisms asserts that further research is required.

Identification of genetic factors would provide important insights into the pathogenesis of tinnitus, facilitate understanding of the course and severity of tinnitus burden on patients, and permit novel diagnostic strategies. The majority of research investigations dissecting the genetics of tinnitus have taken the form of association studies that have revealed few borderlinesignificant results (Table 2). Recently, a genome-wide association study (GWAS) has identified potential metabolic pathways meriting further investigation (Gilles et al., 2017) and two twinstudy cohorts have uncovered heritability estimates that provide pioneering insight into moderate genetic influences for tinnitus (Bogo et al., 2016; Maas et al., 2017). Although an excellent review discussing the genetics of tinnitus that touches upon phenotyping strategies and proposed pathophysiological mechanisms has been recently published (Lopez-Escamez et al., 2016), the present review exclusively emphasizes the genetic studies that have been published to date, discusses emerging data that suggests a complex or multifactorial genetic etiology, and presents an outlook for future research.

\section{COMPLEX GENETICS APPROACHES}

Heritability of tinnitus is defined as tinnitus variance explained by additive genetic factors. The earliest attempts of estimating the heritability of tinnitus stemmed from large family-based questionnaire studies. One of these studies assessed familial aggregation in seven European countries that proposed a siblingsibling tinnitus correlation of 0.16 in 981 siblings and an increased 1.7-fold likelihood of developing tinnitus with an affected sibling. However, the authors rationalized that this could be due to increased tinnitus awareness within families (Hendrickx et al., 2007). Another study analyzed questionnaire data in Norwegian nuclear families and considered genetic and environmental effects in subjects reporting tinnitus (Kvestad et al., 2010). Heritability estimates returned an upper limit value of 0.11 . Criticisms of this study remarked on a lack of attention to questionnaire design and phrasing. Additionally, although the study was conducted as a family-based approach, tinnitus subtyping of the 28,066 participating individuals was not undertaken and similar replication studies have not followed (Sand, 2011).

Despite the considerable prevalence of tinnitus, the lack of Mendelian inheritance and genetic factors implicated from these early studies support that tinnitus is a complex trait. The identification of complex disease alleles is very challenging in the presence of potential genotype-by-environment interaction, incomplete penetrance, environmental phenocopies, genetic heterogeneity, or polygenic inheritance (Lander and Schork, 1994; Silverman and Palmer, 2000). Complex genetic disorders result from relatively common variants in multiple genes that each contribute effects of varying magnitude and are connected to variants that predispose an individual to a disorder rather than directly causing it (Zondervan and Cardon, 2007). Genetic dissection of tinnitus has followed several different paths that include candidate gene association, twin, and GWAS that are summarized below and in Figure 1.

\section{Association Studies}

Association studies can take the form of hypothesis-driven candidate gene or hypothesis-free GWAS, with the latter described in a subsequent section in this review. Case-control association testing compares genotype frequencies between unaffected and affected individuals and takes considerable differences between these two groups as evidence for or against disease susceptibility. Association studies in complex disorders can yield useful information if findings are replicated, or alternatively, if associations are confirmed with linkage analyses studying large families. Examples of replicated association findings are the discovery of the genes ANXA11 and BTNL2 in sarcoidosis and DTNBP1 and NRG1 in schizophrenia (Riley and Kendler, 2006; Spagnolo and du Bois, 2007). However, such findings are rather rare and many studies run the risk of artefactual positive association due to case-control selection bias, population admixture, or alleles residing in linkage disequilibrium (LD) with an allele directly affecting phenotype expression. Furthermore, in candidate gene association studies, the actual gene(s) of interest must already be identified for sequencing or genotyping. Late-onset disorders make selecting control groups challenging and can present a problem in young asymptomatic or undiagnosed individuals with risk alleles (Silverman and Palmer, 2000).

Case-control association testing has been a relatively widely employed approach and has comprised the majority of genetics research conducted in tinnitus patients to date (Table 2, Figure 1). Tinnitus candidate gene selection has included genes enriched in cardiovascular function $(A C E, A D D 1)$, neurotrophic 
TABLE 1 | Monogenic disorders associated with secondary tinnitus with variable onset and severity.

\begin{tabular}{|c|c|c|c|c|c|}
\hline Gene & DFN Locus & MIM & Gene function & Disorder & References \\
\hline ACTG1 & DFNA20/26 & 102560 & Actin gamma 1 & Autosomal dominant non-syndromic hearing loss & de Heer et al., 2009 \\
\hline AIFM1 & AUNX1 & 300169 & $\begin{array}{l}\text { Apoptosis inducing factor, mitochondria } \\
\text { associated } 1\end{array}$ & X-linked non-syndromic hearing loss & $\begin{array}{l}\text { Wang et al., 2006; } \\
\text { Zong et al., } 2015\end{array}$ \\
\hline ANKH & - & 605145 & $\begin{array}{l}\text { ANKH inorganic pyrophosphate } \\
\text { transport regulator }\end{array}$ & Craniometaphyseal dysplasia & Kornak et al., 2010 \\
\hline ATP1A2 & - & 182340 & $\begin{array}{l}\text { ATPase } \mathrm{Na}^{+} / \mathrm{K}^{+} \text {transporting subunit } \\
\text { alpha } 2\end{array}$ & Familiar basilar migraine & Ambrosini et al., 2005 \\
\hline CEACAM16 & DFNA4B & 614591 & $\begin{array}{l}\text { Carcinoembryonic antigen related cell } \\
\text { adhesion molecule } 16\end{array}$ & Autosomal dominant non-syndromic hearing loss & Wang et al., 2015 \\
\hline $\mathrm{COCH}$ & DFNA9 & 603196 & Cochlin & Autosomal dominant non-syndromic hearing loss & Gallant et al., 2013 \\
\hline COL1A1 & - & 120150 & Collagen, type I, alpha-1 & Osteogenesis imperfecta type I & Kuurila et al., 2003 \\
\hline DTNA & - & 601239 & Dystrobrevin alpha & Autosomal dominant familial Ménière disease & Requena et al., 2015 \\
\hline FAM136A & - & 616275 & $\begin{array}{l}\text { Family with sequence similarity } 136 \\
\text { member A }\end{array}$ & Autosomal dominant familial Ménière disease & Requena et al., 2015 \\
\hline GJB2 & DFNA3A & 121011 & Gap junction protein beta-2 & Autosomal dominant non-syndromic hearing loss & Wang et al., 2017 \\
\hline GJB2 & DFNB1 & 121011 & Gap junction protein beta-2 & Autosomal recessive non-syndromic hearing loss & Dodson et al., 2011 \\
\hline GJB3 & DFNA2A & 603324 & Gap junction protein beta-3 & Autosomal dominant non-syndromic hearing loss & $\begin{array}{l}\text { Coucke et al., 1994; } \\
\text { Xia et al., } 1998\end{array}$ \\
\hline GLA & - & 300644 & Galactosidase, alpha & Fabry disease & $\begin{array}{l}\text { Germain et al., 2002; } \\
\text { Conti and Sergi, } 2003\end{array}$ \\
\hline JAK2 & - & 147796 & Janus kinase 2 & Polycythemia vera & Mihalj et al., 2013 \\
\hline$M T-R N R 1$ & - & 561000 & Mitochondrially encoded 12S RNA & Mitochondrial non-syndromic hearing loss & $\begin{array}{l}\text { Matsunaga et al., 2004; } \\
\text { Bravo et al., } 2006\end{array}$ \\
\hline MYOTA & DFNA11 & 276903 & Myosin VIIA & Autosomal dominant non-syndromic hearing loss & Sun et al., 2011 \\
\hline NAGA & - & 104170 & Alpha-N-acetylgalactosamineidase & Kanzaki disease & Kodama et al., 2001 \\
\hline NF2 & - & 607379 & Neurofibromin 2 & Neurofibromatosis type 2 & Evans et al., 1992 \\
\hline OSBPL2 & DFNA67 & 606731 & Oxysterol-binding protein-like protein 2 & Autosomal dominant non-syndromic hearing loss & Xing et al., 2015 \\
\hline P2RX2 & DFNA41 & 600844 & Purinergic receptor P2X 2 & Autosomal dominant non-syndromic hearing loss & Yan et al., 2013 \\
\hline PRKCB & - & 176970 & Protein kinase $\mathrm{C}$ beta & Autosomal dominant familial Ménière disease & $\begin{array}{l}\text { Martín-Sierra et al., } \\
2016\end{array}$ \\
\hline PRPS1 & DFNX1 & 311850 & $\begin{array}{l}\text { Phosphoribosyl pyrophosphate } \\
\text { synthetase } 1\end{array}$ & X-linked non-syndromic hearing loss & Liu et al., 2010 \\
\hline$S D H B^{*}$ & - & 185470 & $\begin{array}{l}\text { Succinate dehydrogenase complex, } \\
\text { subunit B, iron sulfur protein }\end{array}$ & Paragangliomas 4 & $\begin{array}{l}\text { Bayley et al., 2006; } \\
\text { Sagong et al., } 2016\end{array}$ \\
\hline$S D H C^{*}$ & - & 602413 & $\begin{array}{l}\text { Succinate dehydrogenase complex, } \\
\text { subunit } \mathrm{C} \text {, integral membrane protein, } \\
15-\mathrm{KD}\end{array}$ & Paragangliomas 3 & Bickmann et al., 2014 \\
\hline$S D H D^{*}$ & - & 602690 & $\begin{array}{l}\text { Succinate dehydrogenase complex, } \\
\text { subunit D, integral membrane protein }\end{array}$ & Paragangliomas 1 & $\begin{array}{l}\text { Badenhop et al., 2001; } \\
\text { Tan et al., } 2009\end{array}$ \\
\hline TMC1 & DFNA36 & 606706 & $\begin{array}{l}\text { Transmembrane cochlear expressed } \\
\text { gene } 1\end{array}$ & Autosomal dominant non-syndromic hearing loss & Zhao et al., 2014 \\
\hline
\end{tabular}


TABLE 1 | Continued

\begin{tabular}{|c|c|c|c|c|c|}
\hline Gene & DFN Locus & MIM & Gene function & Disorder & References \\
\hline$V H L$ & - & 608537 & von Hippel-Lindau tumor suppressor & von Hippel-Lindau syndrome & Butman et al., 2007 \\
\hline WFS1 & DFNA6/14/38 & 606201 & $\begin{array}{l}\text { Wolframin ER transmembrame } \\
\text { glycoprotein }\end{array}$ & $\begin{array}{l}\text { Autosomal dominant non-syndromic hearing } \\
\text { loss, low-frequency hearing loss }\end{array}$ & Lesperance et al., 1995 \\
\hline Unknown & DFNA16 & 603964 & - & Autosomal dominant non-syndromic hearing loss & Fukushima et al., 1999 \\
\hline Unknown & DFNA33 & 614211 & - & Autosomal dominant non-syndromic hearing loss & Bönsch et al., 2009 \\
\hline Unknown & DFNA43 & 608394 & - & Autosomal dominant non-syndromic hearing loss & Flex et al., 2003 \\
\hline Unknown & DFNA57 & - & - & Autosomal dominant non-syndromic hearing loss & Bönsch et al., 2008 \\
\hline Unknown & DFNA58 & 615654 & - & Autosomal dominant non-syndromic hearing loss & Lezirovitz et al., 2009 \\
\hline Unknown & DFNY1 & 400043 & - & Y-linked hearing loss & Wang et al., 2013 \\
\hline
\end{tabular}

${ }^{*}$ Pulsatile tinnitus (tympanic paraganglioma) associated.

factors ( $B D N F, G D N F)$, ion recycling pathways (KCNE1, KCNE3, $S L C 12 A 2), G A B A_{B}$ receptor subunit (KCTD12), and serotonin receptor/transporter (HTR1A, SLC6A4) function. Presently, nine case-control studies have examined a combined total of 18 genes that are summarized in Table 2 (Kleinjung et al., 2006; Deniz et al., 2010; Sand et al., 2010, 2011, 2012a,b; Pawełczyk et al., 2012; Orenay-Boyacioglu et al., 2016; Yüce et al., 2016). For brevity, we describe selected case-control association studies with potentially significant results.

\section{Cardiovascular-Associated Gene}

ADD1 encodes ubiquitously expressed alpha-adducin. A well-studied polymorphism (p.G460W) has been linked to cardiovascular disease and hypertension (Staessen and Bianchi, 2005). Hypertension-associated auditory primary lesion sites are the organ of Corti and stria vascularis (Gates et al., 1993). An association study investigated the relationship between severe chronic tinnitus and the p.G460W polymorphism in 89 patients with severe chronic tinnitus and 104 age-matched Turkish-Caucasian controls (Yüce et al., 2016). Clinical tinnitus evaluation and severity assessment were performed by the Structured Tinnitus Interview and the Tinnitus Handicap Inventory, respectively. PCR-based restriction fragment length polymorphism (RFLP) analysis of the ADD1 GW genotype ( $p=$ $\left.0.009, \chi^{2}=9.4\right)$ and the $\mathrm{W}$ allele $\left(p=0.021, \chi^{2}=5.3\right)$ revealed significantly increased allele frequencies in the patient group (Yüce et al., 2016). This study asserted the potential involvement of the p.G460W genotype and $\mathrm{W}$ allele in $A D D 1$ in tinnitus pathophysiology.

\section{Neurotrophic Factors}

Tinnitus is thought to stem from central nervous system hyperexcitability and auditory cortical neuronal plasticity. Accumulating evidence indicates that tinnitus adaptation is dependent on cortical tonotopic map remodeling (Eggermont, 2016). An understanding of neurotrophins as important drivers of neural circuit remodeling in the auditory pathway have rationalized their relevance as candidate genes for tinnitus (Tan et al., 2007; Sand et al., 2012b).

PCR-based RFLP analysis in 240 German patients with Tinnitus Questionnaire (TQ)-scored subjective chronic primary tinnitus (Goebel and Hiller, 1994) has been performed for the genes $B D N F$ and GDNF, encoding brain and glial cellderived neurotrophic factors, respectively (Sand et al., 2012b). Both genes are essential in early central auditory pathway development. Two and three markers were investigated in BDNF (rs2049046 and rs6265) and GDNF (rs1110149, rs884344, and rs3812047), respectively. Comparison with reference data did not show significance after multiple testing correction; however, the authors could not exclude a weak modulatory effect. Furthermore, questionnaire intensity scores did not correlate with genetic variants, although notably, age-corrected multiple regression models with joint BDNF and GDNF genotypes indicated tinnitus severity could be predicted in women ( $p=0.04$, uncorrected; Sand et al., 2012b).

These three GDNF markers were similarly screened in a replication study including 52 Turkish patients with chronic tinnitus and 42 controls aged between 18 and 55 years (OrenayBoyacioglu et al., 2016). No statistically significant distribution was detected in allele frequencies for all three markers between tinnitus and control groups. The only parameter reaching significance was heterozygosity (C:G) in the SNP rs1110149 $\left(p=0.02, \chi^{2}\right)$, that was found to have a lower frequency in tinnitus patients compared to controls (Orenay-Boyacioglu et al., 2016).

\section{Potassium Recycling Pathway Genes}

Pharmacological research has highlighted ion regulation and transport as potential therapeutic targets (Sand et al., 2011). Voltage-gated ion channels that are involved in auditory neural transmission by regulating endocochlear potentials are intriguing for exploration of tinnitus pathophysiology (Sand et al., 2010). The genes KCNE1 and SLC12A2 each encode a homologous $\beta$-potassium channel subunit and an inner ear $\mathrm{Na}^{+} / 2 \mathrm{Cl}^{-} / \mathrm{K}^{+}$ co-transporter, respectively, which have been screened in casecontrol association studies (Sand et al., 2010; Pawełczyk et al., 2012).

KCNE1 screening in 201 Caucasian chronic TQ-scored tinnitus patients detected four coding and three non-coding variants, including one novel p.Val47Ile substitution and another novel $3^{\prime}$ UTR variant that were concluded as having a nonsignificant ( $p=0.05$, Fisher's exact test) dominant genotype or compound genotype effect without correction for multiple 


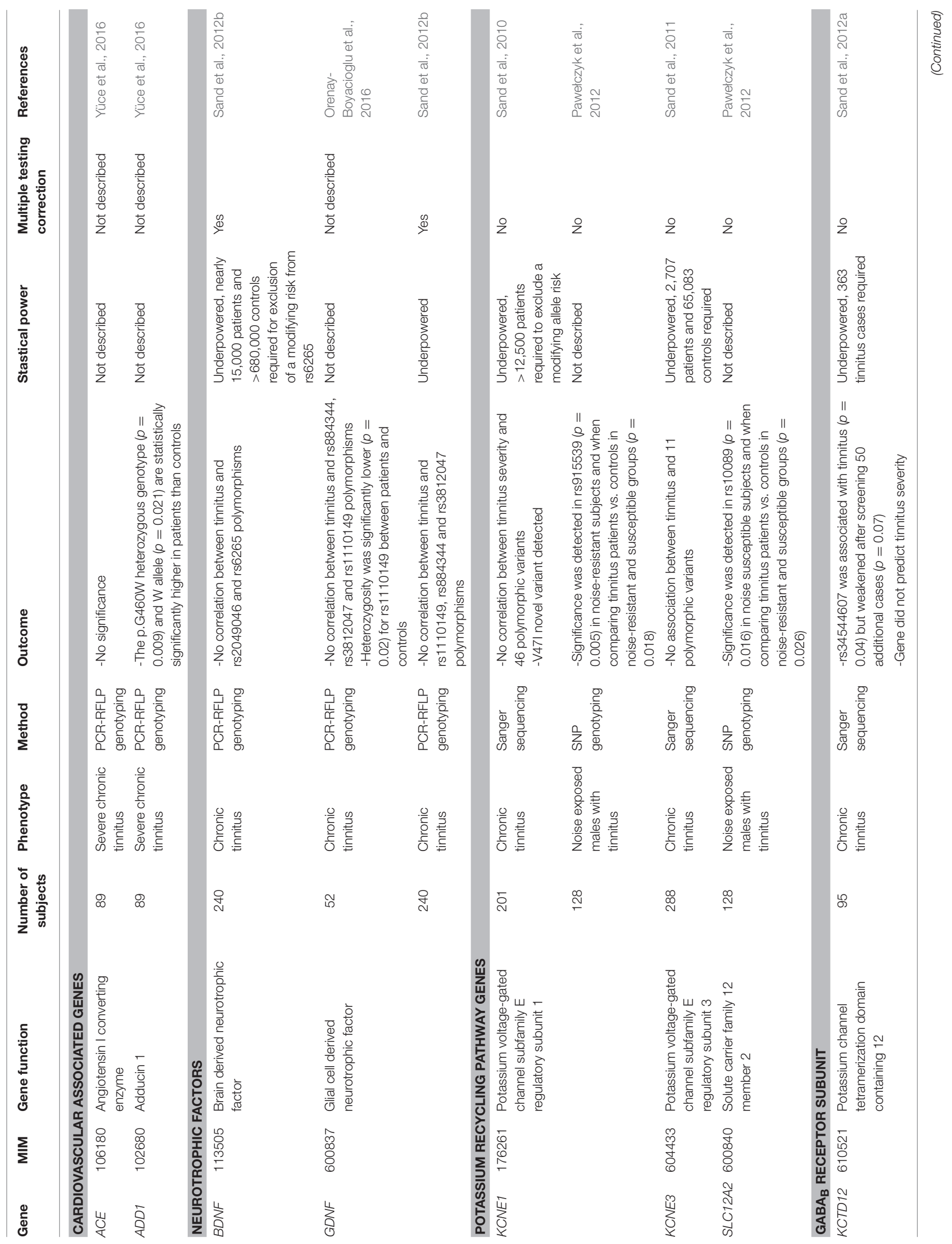




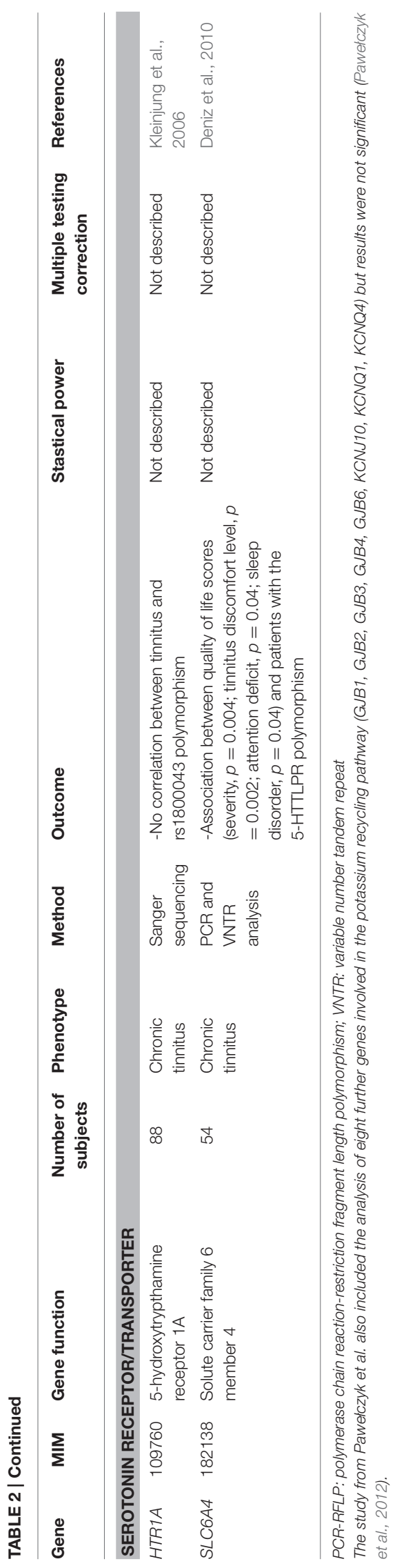

testing (Sand et al., 2010). These variants were not found to be causal by themselves or in compound heterozygosity for chronic TQ-scored tinnitus.

In a Polish genotyping study that included 10 potassium recycling genes, 128 noise-exposed subjects with tinnitus, and 498 noise-exposed controls responded to a questionnaire and underwent analysis. Case and control groups were divided into noise-resistant (normal audiograms) and noise-susceptible (abnormal audiograms) groups and individuals with a family history of hearing loss and other clinical indications or medication exposures were excluded. KCNE1 and SLC12A2 were associated with tinnitus based on significance in only one genetic marker per gene ( $r$ s915539 in KCNE1, $p=0.018$; rs10089 in $S L C 12 A 2, p=0.026$ ). $p$-values were not subjected to multiple testing correction and, therefore, suggested as nominally significant results (Pawełczyk et al., 2012).

\section{GABA $_{B}$ Receptor Subunit}

Abundant data support chronic tinnitus with neuronal hyperactivity at different levels of the central auditory pathway, making drugs that increase inhibitory neurotransmission or block excitatory neurotransmission candidates for the treatment of tinnitus, and genes encoding these respective receptor complexes of potential interest (Eggermont and Roberts, 2004; Wang et al., 2011; Smith et al., 2012; Sand et al., 2012a). The gene KCTD12 encodes a potassium channel tetramerization domain-containing protein that is tightly associated with the $\mathrm{GABA}_{\mathrm{B} 2}$ receptor carboxy-terminus (Sand et al., 2012a) and was subsequently subjected to association testing. The genomic DNAs from 95 German chronic TQ-scored tinnitus patients were obtained and the KCTD12 open reading frame and adjacent $3^{\prime}$ untranslated regions were sequenced. Two rare synonymous and non-coding heterozygous variants were detected. Further, analysis disclosed one significant tinnitus-associated variant (rs34544607; $p=0.04$, Fisher's exact test), but this significance weakened after screening 50 additional cases ( $p=0.07$, Fisher's exact test). No novel variants were detected and no variants were correlated with or predicted intensity of tinnitus; however, the authors acknowledge the study was underpowered.

\section{Serotonin Transporter}

There is considerable overlap in patients reporting disabling tinnitus in conjunction with other comorbidities and a particularly strong association among patients with comorbid depressive disorder that affects $\sim 5-10 \%$ of the general population. There is an estimated $30 \%$ concordant overlap between comorbid depressive disorder and tinnitus that implies common molecular mechanisms and, therefore, overlapping genes attributing to both phenotypes (Tyler et al., 2006). As such, genes involved in serotonin regulation, a critical process associated with depressive psychiatric disorders, have been proposed as tinnitus candidate genes. Serotonin is present in hair cells, eighth nerve fibers, brainstem auditory nuclei and nuclei of the lateral lemniscus and superior olivary complex (Tyler et al., 2006).

The gene SLC6A4 regulates serotonin neurotransmission and has been evaluated for tinnitus-association (Tyler et al., 

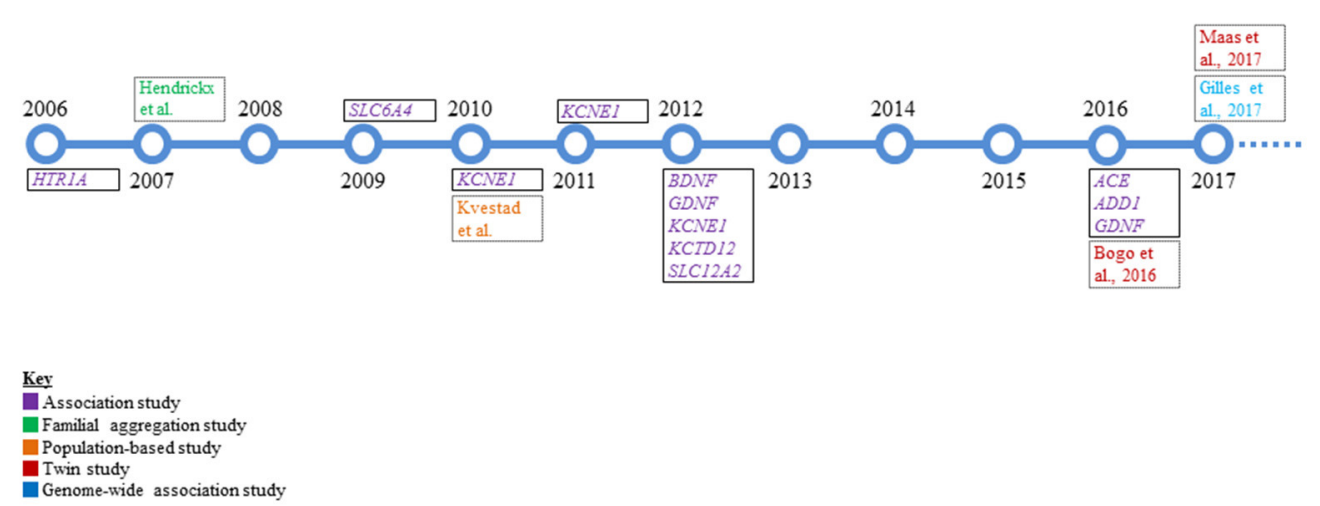

FIGURE 1 | A timeline overview of the genetic research in tinnitus that has been conducted to date. Single genes that were studied via candidate gene association analysis are boxed with a solid black line and represent the majority of work performed in the genetics of tinnitus. All other studies are boxed with a dotted black line.

2006; Deniz et al., 2010). A functional 5'-HTTLPR 44 base pair insertion-deletion polymorphism in the promoter region has been implicated in major depressive disorder (Hoefgen et al., 2005). This polymorphism and a 17 base pair variable number tandem repeat region in intron 2 were screened in 54 patients with subjective tinnitus and 174 population-matched controls. Tinnitus severity and psychoacoustic characteristics were assessed using the Beck Depression Inventory and visual analog scale, respectively. A significant association was detected between the $5^{\prime}$-HTTLPR polymorphism and visual analog scores that measured tinnitus quality of life impact using $\chi^{2}$ tests (severity, $p=0.004$; tinnitus discomfort level, $p=0.002$; attention deficit, $p=0.04$; sleep disorder, $p=0.04$ ). This study linked a polymorphism in the SLC6A4 promoter with neurophysiological symptoms in tinnitus patients (Deniz et al., 2010).

\section{GWAS}

GWAS can be powerful for the association of common variants and genetic loci in complex disorders and are appropriate for dissection of the "common disease-common variant" hypothesis. This hypothesis assumes a significant proportion of phenotypic divergence arises from common variants, typically with a minor allele frequency $>5 \%$, and that these variants are important for disease susceptibility (Sharma et al., 2014).

GWAS utilizes up to several million SNP genotypes most commonly generated from genotyping arrays to tag haplotype blocks, occasionally spanning more than $100 \mathrm{~kb}$, on which functional variants reside. These studies utilize non-random co-inheritance of variants in linkage disequilibrium (LD) to test for case-control trait association (Edwards et al., 2013). pvalue thresholds for statistical significance are very rigorous, typically below $10^{-9}$, to reduce the likelihood of false positive results, accommodate multiple testing burden, and provide enough stringency in studies that include lower frequency variants (minor allele frequency >5\%; LaFramboise, 2009; Fadista et al., 2016). The conclusion after a successful GWAS is that one or more tag SNPs co-reside on haplotype blocks with variants having a biological function related to the phenotype. Interestingly, over $90 \%$ of disease-associated variants from GWAS reside in non-coding regions associated with transcriptional regulatory mechanisms involving promoter and enhancer element modulation (Maurano et al., 2012; Edwards et al., 2013). Following detection of statistically significant association signals, replication and functional experiments are required. A deeper understanding of these variants in a biological context requires experiments analyzing pathogenicity mechanisms such as transcriptional regulation, non-coding RNA function, and epigenetic regulation (Edwards et al., 2013). Functional assessment includes expression quantitative trait loci testing, in vitro protein and chromatin-structure assay analysis, as well as model organism experiments (Lee et al., 2014).

The first cross-sectional pilot tinnitus GWAS in ethnically homogeneous individuals between 55 and 65 years old was performed using 167 individuals with tinnitus and 749 nontinnitus controls from Belgium (Gilles et al., 2017). These patients were previously included in a GWAS for age-related hearing loss in which a polygenic architecture was detected (Fransen et al., 2015). The association between tinnitus phenotype and 4,000,000 SNPs was tested and a gene-set enrichment analysis followed. $3.2 \%$ of the phenotypic variance was due to additive genetic effects. Although none of the SNPs reached genome-wide significance, potentially attributed to the limited sample size, the most interesting associations were revealed in the gene-set enrichment analysis that showed significance in seven metabolic pathways. The three most prominent pathways detected were the nuclear factor erythroid 2 like 2 (NRF2)mediated oxidative stress response, endoplasmic reticulum (ER) stress response and serotonin reception mediated signaling pathways with low FDR-corrected $p$-values ranging from 0.004 to 0.02 . NRF2-mediated oxidative stress plays a role in noiseinduced hearing loss and tinnitus. Interestingly, tinnitus patients have been identified with substantially increased oxidative index levels compared to controls (Delmaghani et al., 2015; Koç et al., 2016). Moreover, ER stress has been associated with 
hearing loss via apoptosis (Van Rossom et al., 2015; Xue et al., 2016). Delayed hearing loss progression has been shown in transgenic mice with ER stress inhibitor treatment ( $\mathrm{Hu}$ et al., 2016). Evidence of serotonin receptor mediated pathway involvement has been proposed from an apparent beneficial outcome of antidepressant usage among tinnitus patients (Baldo et al., 2012). Other pathways reaching significance include RAS, vascular smooth muscle contraction, coenzyme A biosynthesis, and NDK dynamin pathways (Gilles et al., 2017). Several limitations described by the authors included limited power to detect significant individual tinnitus-associated SNPs, the sample set was not selectively enriched for tinnitus patients and comprehensive controlling for risk factors was not undertaken. However, insight into seven potentially implicated pathways in tinnitus was highlighted from gene-set enrichment analysis.

\section{Twin Studies}

Twin-based epidemiological studies serve as a means to estimate heritability by comparing disease concordance in monozygotic (MZ) vs. dizygotic (DZ) twins. Increased concordance in genetically identical MZ vs. DZ twins, who share on average half of their alleles, suggests a role for genetic factors. It is assumed both $\mathrm{MZ}$ and $\mathrm{DZ}$ twins share the same family environment, thus yielding important information about the contribution of genetic factors to disease etiology. Two recent twin studies have been published. While there are differences in the experimental approaches that are detailed below, they independently concluded that genetic factors contribute to tinnitus.

A twin study by Bogo and colleagues evaluated the genetic effects of self-reported tinnitus in male twins aged 52-96 years who were included in a previous longitudinal study (Bogo et al., 2015) that analyzed genetic influence of age-related hearing loss. Male MZ and DZ twins who were born between 1914 and 1958 were included in baseline ( $n=1084$ individuals) and follow-up ( $n=576$ individuals) assessments 18 years apart that included audiometry and self-reported answers to questions about tinnitus status and severity. The hypothesis was that individuals with faster hearing deterioration had the greatest tinnitus risk and that genetic factors influenced tinnitus (Bogo et al., 2016).

No difference in tinnitus prevalence between MZ and DZ twins at either time point was detected and those who reported tinnitus disclosed a mild severity. Individuals $(n=576)$ were placed in one of four categories (never reported tinnitus, $n=361$; tinnitus only at baseline, $n=24$; tinnitus only at follow-up, $n=139$; and tinnitus at both time points, $n=52$ ). Those who reported tinnitus at baseline and both baseline and follow-up assessments showed remarkably poorer hearing at follow-up across all frequencies compared to the reference group (those never reporting tinnitus). Those with tinnitus only at follow-up did not have significantly different hearing thresholds compared to the reference group. MZ twin concordant rates were much higher than for DZ twins at both time points (baseline: MZ 0.46; DZ 0.07; follow-up: MZ 0.51; DZ 0.32), proposing that genetic factors were important. A genetic correlation measuring the extent of genetic influences correlated in tinnitus and hearing thresholds ranged from 0.33 to 0.49 , and suggested a partial overlap of genes associated with tinnitus and hearing loss; however, the authors also concluded that most of the genetic variation in tinnitus was unique to tinnitus and not associated with co-occurring hearing loss. There was a greater hearing threshold difference between discordant DZ twin-pairs compared to MZ twin-pairs in cases and controls. Interestingly, the hearing thresholds among MZ twins discordant for tinnitus were more similar than for discordant DZ twins, which may be due to genetic background. Compared to controls, individuals with tinnitus have statistically significant hearing threshold shifts. An overall heritability of 0.4 was calculated, which demonstrates a moderate genetic influence on tinnitus. The authors disclosed that their study was underpowered, and that noise exposure and other risk factors were not assessed (Bogo et al., 2016).

Another twin study by Maas and colleagues took a slightly different approach and controlled for tinnitus laterality but did not assess hearing thresholds (Maas et al., 2017). Cross-sectional data from the Swedish Twin Registry, that includes participants from the "Screening Across the Lifespan Twin study" and the "Study of Twin Adults: Genes and Environment" (Magnusson et al., 2013) who were born between 1900 and 1985. Concordance rates between $\mathrm{MZ}$ and $\mathrm{DZ}$ twin-pairs $(n=10,464$ twin pairs) were assessed. As opposed to the previously described study that enrolled only male twins, this study also included oppositesexed DZ twins to assess differences due to sex and shared environments. A higher concordance of tinnitus was observed in MZ twins (0.32) vs. DZ twins (0.20). Concordance between DZ same-sex (0.20) and opposite-sex (0.19) twins, same-sex male DZ (0.11) vs. same-sex female DZ (0.13), as well as male MZ (0.25) vs. female MZ (0.23) were all similar. When comparing bilateral tinnitus concordance in both twin groups, a higher concordance rate was detected in MZ (0.49) vs. DZ (0.30) twins that was observed in both sexes. Younger MZ females (0.39) had a greater concordance than DZ females (0.20), but this was not observed in males. Heritability was greater in men (0.68) than in women (0.41), except when considering female twins younger than 40 years of age, where a heritability of 0.62 was determined, although it was noted by the authors that this was a highly variable group. Overall, this study concluded that while tinnitus may be environmentally driven, bilateral tinnitus may have a genetic etiology (Maas et al., 2017).

\section{APPROACHES FOR FUTURE GENETIC STUDIES}

Recently published data have begun to dissect a complex genetic basis for tinnitus. However, the general lack of consistent results is not surprising considering that the type of studies presently conducted have not been optimized through streamlined clinical patient classification criteria or by employing enhanced testing strategies of sufficient statistical power for tinnitus studies. There are many lessons that can be learned from previous analyses that include stratified patient selection and careful design of human genetic studies. 


\section{Addressing Phenotypic Heterogeneity in Tinnitus Genetics Studies}

Identifying the most homogeneous tinnitus patients in terms of etiology, age, sex, severity, onset, and audiometric profile will increase study robustness by limiting genetic variance that would be expected if tinnitus is associated with these factors (Lopez-Escamez et al., 2016). Furthermore, consideration for cooccurring psychiatric disorders and quality of life evaluations are important to recognize as potentially contributing determinants (Langguth et al., 2013). The present collection of case-control association studies has grouped patients into unspecific "chronic tinnitus" cohorts from questionnaire data and only occasionally accounted for concomitant hearing loss, impeding the selection of stratified patient groups. The clinically heterogeneous nature of tinnitus makes assigning patients to one of many clinical subcategories difficult. Current tinnitus assessments are comprised of self-report questionnaires and psychoacoustic measures (Langguth et al., 2013). There have been several classification systems proposed that consider the origin (i.e., auditory system or head and neck) or classify tinnitus according to auditory, somatosensory or psychopathology alterations (Levine and Oron, 2015). Homogeneous patient selection relies on accurate patient sub-typing; however, the present definition of tinnitus sub-types lacks consensus and is complicated by the many recognized etiologies and risk factors (Lopez-Escamez et al., 2016). The application of universal assessment protocols by clinicians would potentially benefit genetics studies in that once genetic datasets are obtained, the merging of multiple datasets by collaborating working groups can be streamlined to enhance recruitment of the several thousand patients and controls required for adequate statistical power. Furthermore, there are over 100 instruments available for clinical trial primary outcome measures, which further asserts there is a lack of tinnitus assessment consensus (Hall et al., 2016; Müller et al., 2016). Determining the standardized instruments used by practitioners would consolidate some of the assessment practices for accurate phenotyping.

\section{Genetic Investigations in Tinnitus}

The unraveling of the human genome has delivered basic knowledge of a reference genome, advanced fundamental knowledge of disease architecture, and catalyzed technological advancements that fuel complex trait research. Recent developments in genetics technology and increased affordability and availability of genotyping array and sequencing data will undoubtedly propel research in the field forward. The present body of research has begun to disclose a genetic architecture for tinnitus but there is still much work ahead for the identification of specific variants influencing critical gene expression and gene products in tinnitus pathophysiology. As previously discussed, study design and patient inclusion are particularly important for a clinically heterogeneous phenotype such as tinnitus. Equally important is the method selection to support appropriate scale and resolution of data for analysis. The next section will discuss the feasibility of case-control association testing, GWAS, and twin and familial approaches in the context of tinnitus research.

\section{Case-Control and Genome-Wide Association Testing in Tinnitus}

Population based association studies have long been a popular strategy to identify polymorphisms correlated with complex traits and have thus far been the most widely employed genetic study in tinnitus genetics research (Table 2). Historically, casecontrol candidate gene studies have not yielded abundant success and independent replications are often not possible. The same problem has also been encountered in tinnitus, which makes a reevaluation of the current and future study designs essential.

Future tinnitus association studies should overcome several problematic design setbacks. One key aspect is to exclude controls with unassessed or unrecognized tinnitus burden and select stratified patient cohorts with sufficient statistical power. Furthermore, control individuals should ideally be matched for age, sex, population background, stress/anxiety traits, and other recognized co-morbidities. Studying already characterized tinnitus patients with homogeneous tinnitus phenotypes, families with transgenerational tinnitus aggregation, or cohorts from previously performed epidemiological health studies where individuals experiencing chronic tinnitus can be re-contacted for in-depth tinnitus scoring and auditory assessment would be beneficial (Lopez-Escamez et al., 2016). Finally, drawing upon knowledge from current GWAS for complex traits such as body weight and neuropsychiatric disorders, tens to hundreds of thousands of cases and controls are required to pinpoint significant loci (Ripke et al., 2014; Locke et al., 2015). However, such studies also underscore the power of a GWAS approach for the association of common variants and genetic loci (LD blocks) with specific diseases or traits. Learning from the scale of studies that are required for other complex traits and considering the clinical complexity of tinnitus, it is likely that future studies in tinnitus need to be increased by several orders of magnitude.

\section{GWAS}

GWAS approaches have successfully dissected the genomic architecture of complex diseases and remain a robust approach for future tinnitus research. Looking more specifically at the collection of studies presently published, it is reasonable to assume several technological advances will transform study designs. The past decade has endowed affordable sequencing technologies that have revolutionized novel gene discovery by providing an avenue from which to effectively approach complex and Mendelian disorders (Koboldt et al., 2013). Next generation sequencing (NGS), also termed high-throughput sequencing, allows parallel amplification and sequencing of the entire protein coding region of the genome (whole exome sequencing) or the entire sequence of an individual's genome (whole genome sequencing). As the majority of significant findings from GWAS are tag SNP haplotype blocks in non-coding regions and NGS provides nucleotide-resolution of scalable coding and non-coding sequence (i.e., whole exome or whole genome sequencing), NGS can be regarded as a complementary methodology to GWAS and both methods have the potential 
to contribute important findings to the field. This would be especially promising if a combination of causal rare coding and common non-coding regulatory variants underlie tinnitus pathology. Examples from Alzheimer and Parkinson disease research underscore this parallel approach from the implication of both common and rare variants in these diseases that were detected from GWAS and NGS approaches, respectively (Sharma et al., 2012, 2014; Guerreiro et al., 2013).

The present collection of case-control studies for tinnitus has emphasized the need for several design considerations. There has yet to be a tinnitus case-control study with adequate statistical power. Complex disorders are more challenging to detect common susceptibility alleles and require larger sample numbers to separate signal from noise and to detect frequent alleles of modest effect (Risch and Merikangas, 1996). Furthermore, population differences can have drastically differing allelic architecture that can complicate the mapping of putative risk factors when attempting association replication in patients of differing ethnicities (Sharma et al., 2014). Although underpowered, even if significance were achieved in the initial association study analyzing GDNF markers in German tinnitus patients, the replication study that followed studied the same three markers in a Turkish tinnitus group (Sand et al., 2012b; Orenay-Boyacioglu et al., 2016).

The only pilot tinnitus GWAS published to date in a Belgian tinnitus cohort has highlighted the worthwhile investment of this approach in tinnitus patients (Gilles et al., 2017). In light of these results, it would be worth repeating a GWAS with a stratified patient cohort of extremely severe tinnitus patients or patients who are young and therefore have a greater chance of having tinnitus due to a genetic etiology. The patients included would need to have the same tinnitus sub-type and controls should be specifically assessed for tinnitus. Replication using a tinnitus cohort would be important to highlight the same pathways and potentially achieve genome-wide significance.

\section{Familial Aggregation and Twin Studies}

Early studies utilizing questionnaire data from families with tinnitus returned low heritability estimates. Although both of the twin studies that have been performed each had their limitations and utilized different inclusion criteria, these recently published studies served as groundbreaking evidence suggesting tinnitus is multifactorial with both genetic and non-genetic factors contributing to its etiology (Bogo et al., 2016; Maas et al., 2017). Another central nervous system disorder, Parkinson disease, has witnessed a similar period of debate about genetic factors contributing to the disease. Early evidence disclosed low heritability estimates from twin studies (Wirdefeldt et al., 2004) and lack of familial aggregation (Levy et al., 2004), while concurrent evidence also uncovered familial aggregation (Maher et al., 2002; Payami et al., 2002; Marder et al., 2003) and heritability estimates were later calculated at 0.34 (Wirdefeldt et al., 2011). Continued research has indeed uncovered the genetic complexity of Parkinson disease. It remains to be seen whether continued research into the genetic underpinnings of tinnitus will uncover similar observations. With respect to twin studies, future studies would have to take into account the same clinical phenotyping and study design details that other genetic studies must also address.

\section{FUTURE OUTLOOK}

Understanding the genetic basis for tinnitus is of great public health significance that is clearly in its infancy. Many of the attempts dissecting the genetic contribution have likely been clouded by tinnitus heterogeneity that emphasizes the need for a consensus for tinnitus measures and increased sample size by several orders of magnitude. Recent heritability estimates from twin studies assert genetic factors are important in tinnitus etiology, which allows a potential understanding of basic molecular mechanisms of tinnitus and eventual diagnostic and therapeutic options. An improvement in study design will further clarify results emerging from genetics studies.

Although gene identification in tinnitus will itself represent a major advancement to the field, it will trigger several new lines of research. (1) Knowledge of candidate genes will permit basic research into the specific pathophysiological mechanisms involving animal models. A recent example is shown in a mouse knockout model with a glutamate aspartate transporter (GLAST) that leaves mice genetically susceptible to tinnitus-inducing agents such as salicylate. Such studies could contribute an understanding to how tinnitus is triggered and maintained (Yu et al., 2016). (2) Streamline effective research into drug development that profits from knowledge of specific mechanisms. (3) Clinical research into genotypephenotype correlations can be based on knowledge of alleles involved. Furthermore, this may also enhance not only diagnostic development to support informed healthcare decisions, but also the identification of high-risk individuals to direct preventative care.

The impact from research breakthroughs analyzing the genetics of tinnitus would be enormous for tinnitus sufferers and would allow personalized and optimized therapies to be possible for tinnitus patients. The most promising data are yet to emerge and will provide much needed insights into the role of genetics in primary chronic tinnitus.

\section{AUTHOR CONTRIBUTIONS}

$\mathrm{BV}, \mathrm{IN}, \mathrm{WS}$, and TH participated in manuscript preparation and editing. All authors have read and approved the final manuscript.

\section{ACKNOWLEDGMENTS}

We acknowledge the COST Action BM1306 TINNET, which supported networking activities. 


\section{REFERENCES}

Ambrosini, A., D’Onofrio, M., Grieco, G. S., Di Mambro, A., Montagna, G., Fortini, D., et al. (2005). Familial basilar migraine associated with a new mutation in the ATP1A2 gene. Neurology 65, 1826-1828. doi: 10.1212/01.wnl.0000187072.71931.c0

Badenhop, R. F., Cherian, S., Lord, R. S., Baysal, B. E., Taschner, P. E., and Schofield, P. R. (2001). Novel mutations in the SDHD gene in pedigrees with familial carotid body paraganglioma and sensorineural hearing loss. Genes Chromosomes Cancer 31, 255-263. doi: 10.1002/gcc.1142

Baguley, D., McFerran, D., and Hall, D. (2013). Tinnitus. Lancet 382, 1600-1607. doi: 10.1016/S0140-6736(13)60142-7

Baldo, P., Doree, C., Molin, P., McFerran, D., and Cecco, S. (2012). Antidepressants for patients with tinnitus. Cochrane Database Syst. Rev. 12:Cd003853. doi: 10.1002/14651858.CD003853.pub3

Bayley, J. P., van Minderhout, I., Weiss, M. M., Jansen, J. C., Oomen, P. H., Menko, F. H., et al. (2006). Mutation analysis of SDHB and SDHC: novel germline mutations in sporadic head and neck paraganglioma and familial paraganglioma and/or pheochromocytoma. BMC Med. Genet. 7:1. doi: 10.1186/1471-2350-7-1

Bickmann, J. K., Sollfrank, S., Schad, A., Musholt, T. J., Springer, E., Miederer, M., et al. (2014). Phenotypic variability and risk of malignancy in SDHClinked paragangliomas: lessons from three unrelated cases with an identical germline mutation (p.Arg133*). J. Clin. Endocrinol. Metab. 99, E489-E496. doi: $10.1210 /$ jc. $2013-3486$

Bogo, R., Farah, A., Johnson, A. C., Karlsson, K. K., Pedersen, N. L., Svartengren, M., et al. (2015). The role of genetic factors for hearing deterioration across 20 years: a twin study. J. Gerontol. A Biol. Sci. Med. Sci. 70, 647-653. doi: 10.1093/gerona/glu245

Bogo, R., Farah, A., Karlsson, K. K., Pedersen, N. L., Svartengren, M., and Skjönsberg, ̊. (2016). Prevalence, Incidence Proportion, and Heritability for Tinnitus: A Longitudinal Twin Study. Ear Hear. doi: 10.1097/AUD.0000000000000397. [Epub ahead of print].

Bönsch, D., Schmidt, C. M., Scheer, P., Bohlender, J., Neumann, C., Am ZehnhoffDinnesen, A., et al. (2009). [A new gene locus for an autosomal-dominant non-syndromic hearing impairment (DFNA 33) is situated on chromosome 13q34-qter]. HNO 57, 371-376. doi: 10.1007/s00106-008-1832-9

Bönsch, D., Schmidt, C. M., Scheer, P., Bohlender, J., Neumann, C., Am Zehnhoff-Dinnesen, A., et al. (2008). [A new locus for an autosomal dominant, non-syndromic hearing impairment (DFNA57) located on chromosome 19p13.2 and overlapping with DFNB15]. HNO 56, 177-182. doi: 10.1007/s00106-007-1633-6

Bravo, O., Ballana, E., and Estivill, X. (2006). Cochlear alterations in deaf and unaffected subjects carrying the deafness-associated A1555G mutation in the mitochondrial 12S rRNA gene. Biochem. Biophys. Res. Commun. 344, 511-516. doi: 10.1016/j.bbrc.2006.03.143

Butman, J. A., Kim, H. J., Baggenstos, M., Ammerman, J. M., Dambrosia, J., Patsalides, A., et al. (2007). Mechanisms of morbid hearing loss associated with tumors of the endolymphatic sac in von Hippel-Lindau disease. JAMA 298, 41-48. doi: 10.1001/jama.298.1.41

Chapiro, E., Feldmann, D., Denoyelle, F., Sternberg, D., Jardel, C., Eliot, M. M., et al. (2002). Two large French pedigrees with non syndromic sensorineural deafness and the mitochondrial DNA T7511C mutation: evidence for a modulatory factor. Eur. J. Hum. Genet. 10, 851-856. doi: 10.1038/sj.ejhg.5200894

Cheng, J., Zhu, Y., He, S., Lu, Y., Chen, J., Han, B., et al. (2011). Functional mutation of SMAC/DIABLO, encoding a mitochondrial proapoptotic protein, causes human progressive hearing loss DFNA64. Am. J. Hum. Genet. 89, 56-66. doi: 10.1016/j.ajhg.2011.05.027

Conti, G., and Sergi, B. (2003). Auditory and vestibular findings in Fabry disease: a study of hemizygous males and heterozygous females. Acta Paediatr. Suppl. 92, 33-37. discussion: 27. doi: 10.1111/j.1651-2227.2003.tb00219.x

Coucke, P., Van Camp, G., Djoyodiharjo, B., Smith, S. D., Frants, R. R., Padberg, G. W., et al. (1994). Linkage of autosomal dominant hearing loss to the short arm of chromosome 1 in two families. N. Engl. J. Med. 331, 425-431. doi: 10.1056/NEJM199408183310702

de Heer, A. M., Huygen, P. L., Collin, R. W., Oostrik, J., Kremer, H., and Cremers, C. W. (2009). Audiometric and vestibular features in a second Dutch
DFNA20/26 family with a novel mutation in ACTG1. Ann. Otol. Rhinol. Laryngol. 118, 382-390. doi: 10.1177/000348940911800511

Delmaghani, S., Defourny, J., Aghaie, A., Beurg, M., Dulon, D., Thelen, N., et al. (2015). Hypervulnerability to sound exposure through impaired adaptive proliferation of peroxisomes. Cell 163, 894-906. doi: 10.1016/j.cell.2015.10.023

Deniz, M., Bayazit, Y. A., Celenk, F., Karabulut, H., Yilmaz, A., Gunduz, B., et al. (2010). Significance of serotonin transporter gene polymorphism in tinnitus. Otol. Neurotol. 31, 19-24. doi: 10.1097/MAO.0b013e3181c2dcbc

Dodson, K. M., Blanton, S. H., Welch, K. O., Norris, V. W., Nuzzo, R. L., Wegelin, J. A., et al. (2011). Vestibular dysfunction in DFNB1 deafness. Am. J. Med. Genet. A 155a, 993-1000. doi: 10.1002/ajmg.a.33828

Edwards, S. L., Beesley, J., French, J. D., and Dunning, A. M. (2013). Beyond GWASs: illuminating the dark road from association to function. Am. J. Hum. Genet. 93, 779-797. doi: 10.1016/j.ajhg.2013.10.012

Eggermont, J. J. (2016). Effects of long-term non-traumatic noise exposure on the adult central auditory system. Hearing problems without hearing loss. Hear. Res. S0378-5955(16)30442-7. doi: 10.1016/j.heares.2016.10.015

Eggermont, J. J., and Roberts, L. E. (2004). The neuroscience of tinnitus. Trends Neurosci. 27, 676-682. doi: 10.1016/j.tins.2004.08.010

Evans, D. G., Huson, S. M., Donnai, D., Neary, W., Blair, V., Newton, V., et al. (1992). A clinical study of type 2 neurofibromatosis. Q. J. Med. 84, 603-618.

Fadista, J., Manning, A. K., Florez, J. C., and Groop, L. (2016). The (in)famous GWAS $P$-value threshold revisited and updated for low-frequency variants. Eur. J. Hum. Genet. 24, 1202-1205. doi: 10.1038/ejhg.2015.269

Flex, E., Mangino, M., Mazzoli, M., Martini, A., Migliosi, V., Colosimo, A., et al. (2003). Mapping of a new autosomal dominant non-syndromic hearing loss locus (DFNA43) to chromosome 2p12. J. Med. Genet. 40, 278-281. doi: 10.1136/jmg.40.4.278

Fransen, E., Bonneux, S., Corneveaux, J. J., Schrauwen, I., Di Berardino, F., White, C. H., et al. (2015). Genome-wide association analysis demonstrates the highly polygenic character of age-related hearing impairment. Eur. J. Hum. Genet. 23, 110-115. doi: 10.1038/ejhg.2014.56

Fukushima, K., Kasai, N., Ueki, Y., Nishizaki, K., Sugata, K., Hirakawa, S., et al. (1999). A gene for fluctuating, progressive autosomal dominant nonsyndromic hearing loss, DFNA16, maps to chromosome 2q23-24.3. Am. J. Hum. Genet. 65, 141-150. doi: 10.1086/302461

Gallant, E., Francey, L., Fetting, H., Kaur, M., Hakonarson, H., Clark, D., et al. (2013). Novel COCH mutation in a family with autosomal dominant late onset sensorineural hearing impairment and tinnitus. Am. J. Otolaryngol. 34, 230-235. doi: 10.1016/j.amjoto.2012.11.002

Gates, G. A., Cobb, J. L., D’Agostino, R. B., and Wolf, P. A. (1993). The relation of hearing in the elderly to the presence of cardiovascular disease and cardiovascular risk factors. Arch. Otolaryngol. Head Neck Surg. 119, 156-161. doi: 10.1001/archotol.1993.01880140038006

Germain, D. P., Avan, P., Chassaing, A., and Bonfils, P. (2002). Patients affected with Fabry disease have an increased incidence of progressive hearing loss and sudden deafness: an investigation of twenty-two hemizygous male patients. BMC Med. Genet. 3:10. doi: 10.1186/1471-2350-3-10

Gilles, A., Van Camp, G., Van de Heyning, P., and Fransen, E. (2017). A pilot genome-wide association study identifies potential metabolic pathways involved in tinnitus. Front. Psychol. 8:71. doi: 10.3389/fnins.2017.00071

Goebel, G., and Hiller, W. (1994). The tinnitus questionnaire. A standard instrument for grading the degree of tinnitus. Results of a multicenter study with the tinnitus questionnaire. HNO 42, 166-172.

Guerreiro, R., Wojtas, A., Bras, J., Carrasquillo, M., Rogaeva, E., Majounie, E., et al. (2013). TREM2 variants in Alzheimer's disease. N. Engl. J. Med. 368, 117-127. doi: 10.1056/NEJMoa1211851

Hall, D. A., Haider, H., Szczepek, A. J., Lau, P., Rabau, S., Jones-Diette, J., et al. (2016). Systematic review of outcome domains and instruments used in clinical trials of tinnitus treatments in adults. Trials 17, 270. doi: 10.1186/s13063-016-1399-9

Hendrickx, J. J., Huyghe, J. R., Demeester, K., Topsakal, V., Van Eyken, E., Fransen, E., et al. (2007). Familial aggregation of tinnitus: a European multicentre study. B-ENT 3(Suppl. 7), 51-60.

Hoefgen, B., Schulze, T. G., Ohlraun, S., von Widdern, O., Höfels, S., Gross, M., et al. (2005). The power of sample size and homogenous sampling: association between the 5-HTTLPR serotonin transporter 
polymorphism and major depressive disorder. Biol. Psychiatry 57, 247-251. doi: 10.1016/j.biopsych.2004.11.027

Hu, J., Li, B., Apisa, L., Yu, H., Entenman, S., Xu, M., et al. (2016). ER stress inhibitor attenuates hearing loss and hair cell death in Cdh23erl/erl mutant mice. Cell Death Dis. 7:e2485. doi: 10.1038/cddis.2016.386

Kleinjung, T., Langguth, B., Fischer, B., Hajak, G., Eichhammer, P., and Sand, P. G. (2006). Systematic screening of the seratonin receptor 1A (5-HT1A) gene in chronic tinnitus. J. Otol. 1, 83-85. doi: 10.1016/S1672-2930(06) 50018-2

Koboldt, D. C., Steinberg, K. M., Larson, D. E., Wilson, R. K., and Mardis, E. R. (2013). The next-generation sequencing revolution and its impact on genomics. Cell 155, 27-38. doi: 10.1016/j.cell.2013.09.006

Koç, S., Akyüz, S., Somuk, B. T., Soyalic, H., Yilmaz, B., Taskin, A., et al. (2016). Paraoxonase activity and oxidative status in patients with tinnitus. J. Audiol. Otol. 20, 17-21. doi: 10.7874/jao.2016.20.1.17

Kodama, K., Kobayashi, H., Abe, R., Ohkawara, A., Yoshii, N., Yotsumoto, S., et al. (2001). A new case of alpha-N-acetylgalactosaminidase deficiency with angiokeratoma corporis diffusum, with Meniere's syndrome and without mental retardation. Br. J. Dermatol. 144, 363-368. doi: 10.1046/j.1365-2133.2001.04028.x

Kornak, U., Brancati, F., Le Merrer, M., Lichtenbelt, K., Höhne, W., Tinschert, S., et al. (2010). Three novel mutations in the ANK membrane protein cause craniometaphyseal dysplasia with variable conductive hearing loss. Am. J. Med. Genet. A 152a, 870-874. doi: 10.1002/ajmg.a.33301

Kubisch, C., Schroeder, B. C., Friedrich, T., Lütjohann, B., El-Amraoui, A., Marlin, S., et al. (1999). KCNQ4, a novel potassium channel expressed in sensory outer hair cells, is mutated in dominant deafness. Cell 96, 437-446. doi: 10.1016/S0092-8674(00)80556-5

Kuurila, K., Kentala, E., Karjalainen, S., Pynnönen, S., Kovero, O., Kaitila, I., et al. (2003). Vestibular dysfunction in adult patients with osteogenesis imperfecta. Am. J. Med. Genet. A 120a, 350-358. doi: 10.1002/ajmg.a.20088

Kvestad, E., Czajkowski, N., Engdahl, B., Hoffman, H. J., and Tambs, K. (2010). Low heritability of tinnitus: results from the second NordTrøndelag health study. Arch. Otolaryngol. Head Neck Surg. 136, 178-182. doi: 10.1001 /archoto.2009.220

LaFramboise, T. (2009). Single nucleotide polymorphism arrays: a decade of biological, computational and technological advances. Nucleic Acids Res. 37, 4181-4193. doi: 10.1093/nar/gkp552

Lander, E. S., and Schork, N. J. (1994). Genetic dissection of complex traits. Science 265, 2037-2048. doi: 10.1126/science.8091226

Langguth, B., Kreuzer, P. M., Kleinjung, T., and De Ridder, D. (2013). Tinnitus: causes and clinical management. Lancet Neurol. 12, 920-930. doi: 10.1016/S1474-4422(13)70160-1

Lee, S., Abecasis, G. R., Boehnke, M., and Lin, X. (2014). Rare-variant association analysis: study designs and statistical tests. Am. J. Hum. Genet. 95, 5-23. doi: 10.1016/j.ajhg.2014.06.009

Lesperance, M. M., Hall, J. W. III, Bess, F. H., Fukushima, K., Jain, P. K., Ploplis, B., et al. (1995). A gene for autosomal dominant nonsyndromic hereditary hearing impairment maps to 4p16.3. Hum. Mol. Genet. 4, 1967-1972. doi: $10.1093 / \mathrm{hmg} / 4.10 .1967$

Levine, R. A., and Oron, Y. (2015). Tinnitus. Handb. Clin. Neurol. 129, 409-431. doi: 10.1016/B978-0-444-62630-1.00023-8

Levy, G., Louis, E. D., Mejia-Santana, H., Côté, L., Andrews, H., Harris, J., et al. (2004). Lack of familial aggregation of Parkinson disease and Alzheimer disease. Arch. Neurol. 61, 1033-1039. doi: 10.1001/archneur.61.7.1033

Lezirovitz, K., Braga, M. C., Thiele-Aguiar, R. S., Auricchio, M. T., Pearson, P. L., Otto, P. A., et al. (2009). A novel autosomal dominant deafness locus (DFNA58) maps to 2p12-p21. Clin. Genet. 75, 490-493. doi: 10.1111/j.1399-0004.2008.01130.x

Liu, X., Han, D., Li, J., Han, B., Ouyang, X., Cheng, J., et al. (2010). Lossof-function mutations in the PRPS1 gene cause a type of nonsyndromic X-linked sensorineural deafness, DFN2. Am. J. Hum. Genet. 86, 65-71. doi: 10.1016/j.ajhg.2009.11.015

Locke, A. E., Kahali, B., Berndt, S. I., Justice, A. E., Pers, T. H., Day, F. R., et al. (2015). Genetic studies of body mass index yield new insights for obesity biology. Nature 518, 197-206. doi: 10.1038/nature14177

Lopez-Escamez, J. A., Bibas, T., Cima, R. F., Van de Heyning, P., Knipper, M., Mazurek, B., et al. (2016). Genetics of tinnitus: an emerging area for molecular diagnosis and drug development. Front. Neurosci. 10:377. doi: $10.3389 /$ fnins.2016.00377

Maas, I. L., Brüggemann, P., Requena, T., Bulla, J., Edvall, N. K., Hjelmborg, J. v. B., et al. (2017). Genetic susceptibility to bilateral tinnitus in a Swedish twin cohort. Genet. Med. doi: 10.1038/gim.2017.4. [Epub ahead of print].

Magnusson, P. K., Almqvist, C., Rahman, I., Ganna, A., Viktorin, A., Walum, H., et al. (2013). The Swedish Twin Registry: establishment of a biobank and other recent developments. Twin Res. Hum. Genet. 16, 317-329. doi: $10.1017 /$ thg. 2012.104

Maher, N. E., Golbe, L. I., Lazzarini, A. M., Mark, M. H., Currie, L. J., Wooten, G. F., et al. (2002). Epidemiologic study of 203 sibling pairs with Parkinson's disease: the GenePD study. Neurology 58, 79-84. doi: 10.1212/WNL.58.1.79

Marder, K., Levy, G., Louis, E. D., Mejia-Santana, H., Cote, L., Andrews, H., et al. (2003). Familial aggregation of early- and late-onset Parkinson's disease. Ann. Neurol. 54, 507-513. doi: 10.1002/ana.10711

Martín-Sierra, C., Requena, T., Frejo, L., Price, S. D., Gallego-Martinez, A., Batuecas-Caletrio, A., et al. (2016). A novel missense variant in PRKCB segregates low-frequency hearing loss in an autosomal dominant family with Meniere's disease. Hum. Mol. Genet. 25, 3407-3415. doi: 10.1093/hmg/ddw183

Matsunaga, T., Kumanomido, H., Shiroma, M., Ohtsuka, A., Asamura, K., and Usami, S. (2004). Deafness due to A1555G mitochondrial mutation without use of aminoglycoside. Laryngoscope 114, 1085-1091. doi: 10.1097/00005537-200406000-00024

Maurano, M. T., Humbert, R., Rynes, E., Thurman, R. E., Haugen, E., Wang, H., et al. (2012). Systematic localization of common disease-associated variation in regulatory DNA. Science 337, 1190-1195. doi: 10.1126/science.1222794

Mencía, A., Modamio-Høybjør, S., Redshaw, N., Morin, M., Mayo-Merino, F., Olavarrieta, L., et al. (2009). Mutations in the seed region of human miR96 are responsible for nonsyndromic progressive hearing loss. Nat. Genet. 41, 609-613. doi: 10.1038/ng.355

Mihalj, M., Titlic, M., Bonacin, D., and Dogaš, Z. (2013). Sensomotor axonal peripheral neuropathy as a first complication of polycythemia rubra vera: a report of 3 cases. Am. J. Case Rep. 14, 385-387. doi: 10.12659/AJCR.884016

Modamio-Høybjør, S., Moreno-Pelayo, M. A., Mencía, A., del Castillo, I., Chardenoux, S., Morais, D., et al. (2004). A novel locus for autosomal dominant nonsyndromic hearing loss, DFNA50, maps to chromosome 7q32 between the DFNB17 and DFNB13 deafness loci. J. Med. Genet. 41:e14. doi: 10.1136/jmg.2003.012500

Müller, K., Edvall, N. K., Idrizbegovic, E., Huhn, R., Cima, R., Persson, V., et al. (2016). Validation of Online Versions of Tinnitus Questionnaires Translated into Swedish. Front. Aging Neurosci. 8:272. doi: 10.3389/fnagi.2016. 00272

Orenay-Boyacioglu, S., Coskunoglu, A., Caki, Z., and Cam, F. S. (2016). Relationship between chronic tinnitus and glial cell line-derived neurotrophic factor gene rs3812047, rs1110149, and rs884344 polymorphisms in a Turkish Population. Biochem. Genet. 54, 552-563. doi: 10.1007/s10528-016-9741-1

Pawełczyk, M., Rajkowska, E., Kotyło, P., Dudarewicz, A., Van Camp, G., and Śliwińska-Kowalska, M. (2012). Analysis of inner ear potassium recycling genes as potential factors associated with tinnitus. Int. J. Occup. Med. Environ. Health 25, 356-364. doi: 10.2478/s13382-012-0061-3

Payami, H., Zareparsi, S., James, D., and Nutt, J. (2002). Familial aggregation of Parkinson disease: a comparative study of early-onset and late-onset disease. Arch. Neurol. 59, 848-850. doi: 10.1001/archneur.59.5.848

Requena, T., Cabrera, S., Martín-Sierra, C., Price, S. D., Lysakowski, A., and LopezEscamez, J. A. (2015). Identification of two novel mutations in FAM136A and DTNA genes in autosomal-dominant familial Meniere's disease. Hum. Mol. Genet. 24, 1119-1126. doi: 10.1093/hmg/ddu524

Riley, B., and Kendler, K. S. (2006). Molecular genetic studies of schizophrenia. Eur. J. Hum. Genet. 14, 669-680. doi: 10.1038/sj.ejhg.5201571

Ripke, S., Neale, B. M., Corvin, A., Walters, J. T. R., Farh, K.-H., Holmans, P. A., et al. (2014). Biological insights from 108 schizophrenia-associated genetic loci. Nature 511, 421-427. doi: 10.1038/nature13595

Risch, N., and Merikangas, K. (1996). The future of genetic studies of complex human diseases. Science 273, 1516-1517. doi: 10.1126/science.273.5281.1516

Sagong, B., Seo, Y. J., Lee, H. J., Kim, M. J., Kim, U. K., and Moon, I. S. (2016). A mutation of the succinate dehydrogenase B gene in a Korean family with paraganglioma. Fam. Cancer 15, 601-606. doi: 10.1007/s10689-0169874-8 
Sand, P. G. (2011). Genetic Risk Factors in Chronic Tinnitus. New York, NY: Springer.

Sand, P. G., Langguth, B., Itzhacki, J., Bauer, A., Geis, S., Cárdenas-Conejo, Z. E., et al. (2012a). Resequencing of the auxiliary GABA(B) receptor subunit gene KCTD12 in chronic tinnitus. Front. Syst. Neurosci. 6:41. doi: 10.3389/fnsys.2012.00041

Sand, P. G., Langguth, B., and Kleinjung, T. (2011). Deep resequencing of the voltage-gated potassium channel subunit KCNE3 gene in chronic tinnitus. Behav. Brain Funct. 7:39. doi: 10.1186/1744-9081-7-39

Sand, P. G., Langguth, B., Kleinjung, T., and Eichhammer, P. (2007). Genetics of chronic tinnitus. Prog. Brain Res. 166, 159-168. doi: 10.1016/s0079-6123(07)66014-2

Sand, P. G., Langguth, B., Schecklmann, M., and Klienjung, T. (2012b). GDNF and BDNF gene interplay in chronic tinnitus. Int. J. Mol. Epidemiol. Genet. 3, 245-251.

Sand, P. G., Luettich, A., Kleinjung, T., Hajak, G., and Langguth, B. (2010). An Examination of KCNE1 mutations and common variants in chronic tinnitus. Genes (Basel) 1, 23-37. doi: 10.3390/genes 1010023

Shargorodsky, J., Curhan, G. C., and Farwell, W. R. (2010). Prevalence and characteristics of tinnitus among US adults. Am. J. Med. 123, 711-718. doi: 10.1016/j.amjmed.2010.02.015

Sharma, M., Krüger, R., and Gasser, T. (2012). LRRK2: understanding the role of common and rare variants in Parkinson's disease. Mov. Disord. 27:475. doi: $10.1002 / \mathrm{mds} .24937$

Sharma, M., Krüger, R., and Gasser, T. (2014). From genome-wide association studies to next-generation sequencing: lessons from the past and planning for the future. JAMA Neurol. 71, 5-6. doi: 10.1001/jamaneurol.2013.3682

Silverman, E. K., and Palmer, L. J. (2000). Case-control association studies for the genetics of complex respiratory diseases. Am. J. Respir. Cell Mol. Biol. 22, 645-648. doi: 10.1165/ajrcmb.22.6.f191

Smith, P. F., Zheng, Y., and Darlington, C. L. (2012). Revisiting baclofen for the treatment of severe chronic tinnitus. Front. Neurol. 3:34. doi: 10.3389/fneur.2012.00034

Spagnolo, P., and du Bois, R. M. (2007). Genetics of sarcoidosis. Clin. Dermatol. 25, 242-249. doi: 10.1016/j.clindermatol.2007.03.001

Staessen, J. A., and Bianchi, G. (2005). Adducin and hypertension. Pharmacogenomics 6, 665-669. doi: 10.2217/14622416.6.7.665

Sun, Y., Chen, J., Sun, H., Cheng, J., Li, J., Lu, Y., et al. (2011). Novel missense mutations in MYO7A underlying postlingual high- or low-frequency nonsyndromic hearing impairment in two large families from China. J. Hum. Genet. 56, 64-70. doi: 10.1038/jhg.2010.147

Tan, J., Rüttiger, L., Panford-Walsh, R., Singer, W., Schulze, H., Kilian, S. B., et al. (2007). Tinnitus behavior and hearing function correlate with the reciprocal expression patterns of BDNF and Arg3.1/arc in auditory neurons following acoustic trauma. Neuroscience 145, 715-726. doi: 10.1016/j.neuroscience.2006.11.067

Tan, T. M., Hatfield, E. C., Thakker, R. V., Maher, E. R., Meeran, K., Martin, N. M., et al. (2009). A legacy of tinnitus: multiple head and neck paragangliomas. Rare Tumors 1:e29. doi: 10.4081/rt.2009.e29

Tyler, R. S., Coelho, C., and Noble, W. (2006). Tinnitus: standard of care, personality differences, genetic factors. ORL J. Otorhinolaryngol. Relat. Spec. 68, 14-19. discussion: 20-12. doi: 10.1159/000090486

Van Rossom, S., Op de Beeck, K., Hristovska, V., Winderickx, J., and Van Camp, G. (2015). The deafness gene DFNA5 induces programmed cell death through mitochondria and MAPK-related pathways. Front. Cell. Neurosci. 9:231. doi: 10.3389/fncel.2015.00231

Voo, I., Allf, B. E., Udar, N., Silva-Garcia, R., Vance, J., and Small, K. W. (2003). Hereditary motor and sensory neuropathy type VI with optic atrophy. Am. J. Ophthalmol. 136, 670-677. doi: 10.1016/S0002-9394(03) 00390-8

Wan, J., Mamsa, H., Johnston, J. L., Spriggs, E. L., Singer, H. S., Zee, D. S., et al. (2011). Large genomic deletions in CACNA1A Cause Episodic Ataxia Type 2. Front. Neurol. 2:51. doi: 10.3389/fneur.2011.00051

Wang, H., Brozoski, T. J., and Caspary, D. M. (2011). Inhibitory neurotransmission in animal models of tinnitus: maladaptive plasticity. Hear. Res. 279, 111-117. doi: 10.1016/j.heares.2011.04.004

Wang, H., Wang, X., He, C., Li, H., Qing, J., Grati, M., et al. (2015). Exome sequencing identifies a novel CEACAM16 mutation associated with autosomal dominant nonsyndromic hearing loss DFNA4B in a Chinese family. J. Hum. Genet. 60, 119-126. doi: 10.1038/jhg.2014.114

Wang, H., Wu, K., Yu, L., Xie, L., Xiong, W., Wang, D., et al. (2017). A novel dominant GJB2 (DFNA3) mutation in a Chinese family. Sci. Rep. 7:34425. doi: $10.1038 /$ srep34425

Wang, Q. J., Li, Q. Z., Rao, S. Q., Lee, K., Huang, X. S., Yang, W. Y., et al. (2006). AUNX1, a novel locus responsible for $\mathrm{X}$ linked recessive auditory and peripheral neuropathy, maps to Xq23-27.3. J. Med. Genet. 43:e33. doi: 10.1136/jmg.2005.037929

Wang, Q., Xue, Y., Zhang, Y., Long, Q., and Asan, Y. F. (2013). Genetic basis of Y-linked hearing impairment. Am. J. Hum. Genet. 92, 301-306. doi: 10.1016/j.ajhg.2012.12.015

Wirdefeldt, K., Gatz, M., Reynolds, C. A., Prescott, C. A., and Pedersen, N. L. (2011). Heritability of Parkinson disease in Swedish twins: a longitudinal study. Neurobiol. Aging 32, e1921-e1928. doi: 10.1016/j.neurobiolaging.2011.02.017

Wirdefeldt, K., Gatz, M., Schalling, M., and Pedersen, N. L. (2004). No evidence for heritability of Parkinson disease in Swedish twins. Neurology 63, 305-311. doi: 10.1212/01.WNL.0000129841.30587.9D

Xia, J. H., Liu, C. Y., Tang, B. S., Pan, Q., Huang, L., Dai, H. P., et al. (1998). Mutations in the gene encoding gap junction protein beta-3 associated with autosomal dominant hearing impairment. Nat. Genet. 20, 370-373. doi: $10.1038 / 3845$

Xiao, S., Yu, C., Chou, X., Yuan, W., Wang, Y., Bu, L., et al. (2001). Dentinogenesis imperfecta 1 with or without progressive hearing loss is associated with distinct mutations in DSPP. Nat. Genet. 27, 201-204. doi: 10.1038/84848

Xing, G., Yao, J., Wu, B., Liu, T., Wei, Q., Liu, C., et al. (2015). Identification of OSBPL2 as a novel candidate gene for progressive nonsyndromic hearing loss by whole-exome sequencing. Genet. Med. 17, 210-218. doi: 10.1038/gim.2014.90

Xue, Q., Li, C., Chen, J., Guo, H., Li, D., and Wu, X. (2016). The Protective effect of the endoplasmic reticulum stress-related factors BiP/GRP78 and CHOP/Gadd153 on noise-induced hearing loss in guinea pigs. Noise Health 18, 247-255. doi: 10.4103/1463-1741.192481

Yan, D., Zhu, Y., Walsh, T., Xie, D., Yuan, H., Sirmaci, A., et al. (2013). Mutation of the ATP-gated $\mathrm{P} 2 \mathrm{X}$ receptor leads to progressive hearing loss and increased susceptibility to noise. Proc. Natl. Acad. Sci. U.S.A. 110, 2228-2233. doi: 10.1073/pnas.1222285110

Yüce, S., Sancakdar, E., Bağci, G., Koç, S., Kurtulgan, H. K., Bağci, B., et al. (2016). Angiotensin-Converting Enzyme (ACE) I/D and Alpha-Adducin (ADD1) G460W gene polymorphisms in Turkish Patients with severe chronic tinnitus. J. Int. Adv. Otol. 12, 77-81. doi: 10.5152/iao.2016.1732

Yu, H., Vikhe Patil, K., Han, C., Fabella, B., Canlon, B., Someya, S., et al. (2016). GLAST Deficiency in mice exacerbates gap detection deficits in a model of salicylate-induced tinnitus. Front. Behav. Neurosci. 10:158. doi: 10.3389/fnbeh.2016.00158

Zhao, Y., Wang, D., Zong, L., Zhao, F., Guan, L., Zhang, P., et al. (2014). A novel DFNA36 mutation in TMC1 orthologous to the Beethoven (Bth) mouse associated with autosomal dominant hearing loss in a Chinese family. PLoS ONE 9:e97064. doi: 10.1371/journal.pone.0097064

Zondervan, K. T., and Cardon, L. R. (2007). Designing candidate gene and genome-wide case-control association studies. Nat. Protoc. 2, 2492-2501. doi: $10.1038 /$ nprot.2007.366

Zong, L., Guan, J., Ealy, M., Zhang, Q., Wang, D., Wang, H., et al. (2015). Mutations in apoptosis-inducing factor cause X-linked recessive auditory neuropathy spectrum disorder. J. Med. Genet. 52, 523-531. doi: 10.1136/jmedgenet-2014-102961

Conflict of Interest Statement: The authors declare that the research was conducted in the absence of any commercial or financial relationships that could be construed as a potential conflict of interest.

Copyright (c) 2017 Vona, Nanda, Shehata-Dieler and Haaf. This is an open-access article distributed under the terms of the Creative Commons Attribution License (CC BY). The use, distribution or reproduction in other forums is permitted, provided the original author(s) or licensor are credited and that the original publication in this journal is cited, in accordance with accepted academic practice. No use, distribution or reproduction is permitted which does not comply with these terms. 